\title{
AKTIVITAS ANTIBAKTERI EKSTRAK ETANOL DAUN TALAS KETAN (Colocasia esculenta) TERHADAP BAKTERI Saphylococcus aureus DAN Salmonella thypi SECARA DIFUSI AGAR
}

\author{
Herwin, Muzakkir Baits, Ririn
}

Fakultas Farmasi, Universitas Muslim Indonesia

Email : herwinfarmasi@gmail.com.

\begin{abstract}
Antibacterial activity of taro leaves ekxtract has been conducted. The Recearch aimed to determine the antibacterial activity and concentration of ethanol extract of taro leaves (Colocacia esculeta) inhibited the growth of either Salmonella thypi and Staphylococcus aureus by agar diffusion. The result of the antibacterial activity screening in concentration of $1 \%$ showed that the ethanol extract of taro leaves by solid dilution provided activity againts Salmonella thypii and Staphylococcus aureus. Based on the test results of antibacterial activity by agar diffusion using concentration of $1 \%, 2 \%$ and $4 \%$ showed that the ethanol extract of taro has the largest inhibition zone diameter againts Staphylococcus aureus of $4 \%$ was $15 \mathrm{~mm}$.
\end{abstract}

Keywords : Talas Ketan/Taro leaves (Colocacia esculenta), agar diffusion, Antibacteria.

\section{PENDAHULUAN}

Indonesia merupakan negara yang kaya akan sumber daya alam. Hal ini ditunjang dari iklim tropis yang ada di Indonesia. Dengan sumber daya alam tersebut memiliki banyak potensi yang dapat dimanfaatkan, seperti jenis tumbuhan/tanaman yang dapat dimanfaatkan sebagai obat tradisional. Salah satu tumbuhan yang dapat dimanfaatkan sebagai obat tradisional adalah talas ketan/taro (Colocasia esculenta) dengan berbagai macam kandungan kimia mengandung 6-C-glikosilflavonoid dan O-glikosilflavonoid, diantaranya schaftoside, isoschaftoside, orientin, isovitexin, isoorientin, vitexin dan Iuteolin 7-O-sophoroside. ${ }^{4}$ Dalam penelitian lain disebutkan pula kandungan daun talas diantaranya saponin, terpen, tanin, flavonoid, flobatanin, antraquinon, glikosida jantung, dan alkaloid. ${ }^{1-2}$

Kandungan kimia tersebut mempunyai banyak aktivitas farmakologi seperti tannin, saponin, alkaloid, flavanoid dan lain 
Aktivitas Antibakteri Ekstrak Etanol Daun Talas Ketan (Colocasia esculenta) Terhadap Bakteri Saphylococcus aureus dan Salmonella thypi Secara Difusi Agar

sebagainya. Salah satu kandungan

kimia tersebut seperti tanin merupakan merupakan senyawa polifenol tumbuhan/tanaman. Tanin secara luas digunakan untuk aplikasi di bidang pengobatan yang mempunyai banyak aktivitas farmakologi antara lain sebagai hemostatik, pembalut luka bakar, antimikroba, antidiare, antiinflamsi, antikanker, antioksidan, atheroprotektif. ${ }^{2}$

\section{Daun talas ketan/taro} (Colocasia esculenta) secara empiris digunakan oleh masyarakat sebagai obat scrofula, radang kulit bernanah, psoriasis, tumor di rongga perut, berak darah, keseleo, ketombe, bisul, dan luka bakar. Sementara tangkai dan daunnya digunakan untuk pengobatan urticaria, diare, dan pembalut luka. Hal tersebut dikarenakan tanaman talas mengandung senyawa-senyawa polifenol dan saponin. ${ }^{2}$ Penelitian sebelumnya bahwa ekstrak etanol umbi talas ketan secara KLTBoautografi memberikan aktivitas terhadap bakteri Staphylococcus aureus dan Salmonella thypi dan identifikasi golongan komponen kimia aktif merupakan golongan flavonoid, maka pada penelitian ini perlu dilakukan penelitian aktivitas antibakteri dengan metode lain yaitu secara difusi agar sehingga penggunaannya dalam masyarakat daun talas lebih dapat dipertanggungjawabkan. ${ }^{3}$

\section{METODOLOGI PENELITIAN}

\section{Tempat Penelitian}

Pelaksanaan

penelitian

bertempat

di

Laboratorium

Mikrobiologi Fakultas Farmasi

Universitas Muslim Indonesia.

\section{Alat dan Bahan Penelitian}

Alat-alat yang digunakan pada penelitian ini adalah bejana maserasi, cawan petri (Normax), labu erlenmeyer (Iwake, Pyrex), gelas kimia (Iwake, Pyrex), inkubator (Memmert), mikropipet (Huawei), autoklaf (Smic Model YX-280B), oven (Memmert), enkas, Laminar Air Flow (LAF), spektrofotometri UV-Vis (Genesis), timbangan analitik (Chyo), dan timbangan kasar (O'Haus).

Bahan-bahan yang digunakan pada penelitian ini adalah air suling steril, biakan bakteri ujiStaphylococcus aureus dan Salmonella thypi, dimetil sulfoksida (DMSO), etanol 96\%, medium Nutrient Agar (NA) (Merck), larutan $\mathrm{NaCl}$ fisiologis $0,9 \%$, dan daun talas ketan (Colocasia esculenta).

\section{Prosedur Penelitian}

Sampel umbi talas ketan/taro (Colocasia esculenta) dibersihkan dari kotoran-kotoran yang melekat dengan menggunakan air yang mengalir, 
Aktivitas Antibakteri Ekstrak Etanol Daun Talas Ketan (Colocasia esculenta) Terhadap Bakteri Saphylococcus aureus dan Salmonella thypi Secara Difusi Agar

kemudian dikeringkan dengan cara diangin-anginkan dan tidak terkena sinar matahari langsung. Serbuk daun nampu (Homalomena occulta [Lour].Schott.) ditimbang 200 gram kemudian dimasukkan dalam wadah maserasi. Cairan pengekstraksi yang sesuai sebanyak 2,5 L dimasukkan kedalam wadah maserasi disimpan pada tempat yang terlindungi dari cahaya matahari langsung selama 5 hari sambil diaduk secara periodik. Campuran kemudian disaring dan ampasnya direndam lagi dengan cairan penyari yang baru. Proses penyarian selanjutnya dilakukan sebanyak 2 kali dengan etanol $96 \%$ setiap kali sebanyak 2 L. Ekstrak cair dikumpulkan kemudian dipekatkan dengan menggunakan alat rotavapor hingga diperoleh ekstrak yang kental. ${ }^{5}$

\section{Pengujian Skreening Aktivitas Antibakteri}

Ekstrak etanol daun talas ketan/taro (Colocasia esculenta) ditimbang sebanyak $10 \mathrm{mg}$ lalu dilarutkan dengan DMSO sebanyak $200 \mu \mathrm{l} \quad(0,2 \mathrm{ml})$. Setelah larut ditambahkan medium NA $9,8 \mathrm{ml}$ sehingga diperoleh konsentrasi 1 $\mathrm{mg} / \mathrm{ml}$. Campuran tersebut dituang kedalam cawan petri lalu dihomogenkan dan dibiarkan memadat. Sebagai kontrol positif untuk bakteri digunakan kloramfenikol, dan kontrol negatif digunakan DMSO. Bakteri yang telah disuspensikan, masing-masing diambil $50 \quad \mu l$ menggunkan mikropipet dan digoreskan diatas medium yang telah memadat menggunakan ose bulat. Kemudian diinkubasi pada suhu $37^{\circ} \mathrm{C}$ selama 24 jam. Setelah itu diamati aktivitas antibakterinya yang ditandai dengan ada atau tidaknya pertumbuhan bakteri. $^{6}$

\section{Pengujian Aktivitas Antibakteri} Secara Difusi Agar

Medium NA steril sebanyak 10 $\mathrm{ml}$ dituang kedalam cawan petri dan dibiarkan memadat. Selanjutnya $5 \mathrm{ml}$ medium NA yang telah ditambahkan $20 \mu \mathrm{l} \quad(0,02 \mathrm{ml})$ suspensi bakteri Staphylococcus aureus dan Salmonella thypi, dihomogenkan kemudian dituang dan dibiarkan memadat. Setelah itu, antimicrobial susceptibility test disc dilarutkan dalam sampel ekstrak Colocacia esculentapada kosentrasi $1 \%, 2 \%, 4 \%$ dan dimasukkan dalam cawan petri yang telah berisi medium. Diinkubasi pada suhu $37^{\circ} \mathrm{C}$ selama 24 jam. Lalu diamati dan diukur diameter zona hambatan. ${ }^{7-8}$ 
Aktivitas Antibakteri Ekstrak Etanol Daun Talas Ketan (Colocasia esculenta) Terhadap Bakteri Saphylococcus aureus dan Salmonella thypi Secara Difusi Agar

HASIL PENELITIAN

Hasil ekstraksi umbi talas ketan

(Colocasia esculenta)

Hasil ekstraksi daun talas ketan/taro (Colocasia esculenta) sebanyak 318 gram dengan metode maserasi menggunakan etanol $96 \%$ diperoleh 20 gram ekstrak etanol kental, terlihat pada table 1 .

Tabel 1. Hasil ekstraksi daun talas ketan/taro (Colocasia esculenta).

\begin{tabular}{ccc}
\hline No. & Sampel & Bobot (gram) \\
\hline 1. & Daun talas ketan/taro & 318 \\
2. & Ekstrak etanol & 20 \\
\hline
\end{tabular}

Pengujian skrining antimikroba

Pengujian skrining antimikroba ekstrak etanol Daun talas ketan/taro (Colocasia esculenta) terhadap bakteri ujiSalmonella thypi, Shigella dysentriae, Staphylococcus aureus, Streptococcus mutans, Streptococcus epidermidis, Vibrio cholerae, Pseudomonas aeruginosa, Escherichia coli, dan Bacillus subtilis menunjukkan bahwa ekstrak etanol memberikan aktivitas antibakteri pada semua bakteri uji tersebut, terlihat pada tabel 2.

Tabel 2. Hasil skrining antibakteri ekstrak etanol daun talas ketan/taro (Colocasia esculenta) terhadap beberapa bakteri uji.

\begin{tabular}{lccc}
\hline \multirow{2}{*}{ No } & Sampel & \multicolumn{2}{c}{ Bakteri uji } \\
\cline { 3 - 4 } 1. & Ekstrak etanol & SA & ST \\
\hline
\end{tabular}

Keterangan :

$\mathrm{SA}=$ Staphylococcus aureus

$+\quad=$ menghambat pertumbuhan bakteri

\section{Hasil pengujian Aktivitas}

\section{Antibakteri Secara Difusi Agar}

Pada pengujian ekstrak etanol daun talas ketan/taro (Colocasia esculenta) secara difusi agar terhadap
ST = Salmonella typhi

bakteri Staphylococcus aureus dan Salmonella thypi diperoleh diameter zoa hambatan yang berbeda-beda, terlihat pada tabel 3 . 
Aktivitas Antibakteri Ekstrak Etanol Daun Talas Ketan (Colocasia esculenta) Terhadap Bakteri Saphylococcus aureus dan Salmonella thypi Secara Difusi Agar

Tabel 3. Hasil pengujian aktivitas antibakteri dari ekstrak etanol daun talas ketan/taro (Colocasia esculenta) secara difusi agar.

\begin{tabular}{|c|c|c|c|c|c|c|}
\hline \multirow[t]{2}{*}{ Bakteri Uji } & \multirow[t]{2}{*}{ Replikasi } & \multirow{2}{*}{$\begin{array}{c}\text { Kosentrasi } \\
1 \%\end{array}$} & \multicolumn{3}{|c|}{$\begin{array}{l}\text { Diameter Zona } \\
\text { Hambatan (mm) }\end{array}$} & \multirow{2}{*}{$\begin{array}{c}\text { Rata-Rata } \\
8\end{array}$} \\
\hline & & & 8 & 8 & 8 & \\
\hline \multirow{5}{*}{$\begin{array}{c}\text { Salmonella } \\
\text { thypi }\end{array}$} & $\mathrm{R} 1$ & $2 \%$ & 10 & 10 & 10 & 10 \\
\hline & & $4 \%$ & 12 & 12 & 12 & 12 \\
\hline & & $1 \%$ & 9 & 9 & 9 & 9 \\
\hline & $\mathrm{R} 2$ & $2 \%$ & 11 & 11 & 11 & 11 \\
\hline & & $4 \%$ & 13 & 13 & 13 & 13 \\
\hline \multirow{6}{*}{$\begin{array}{c}\text { Staphylococcus } \\
\text { aureus }\end{array}$} & & $1 \%$ & 9 & 9 & 9 & 9 \\
\hline & R1 & $2 \%$ & 12 & 12 & 12 & 12 \\
\hline & & $4 \%$ & 15 & 15 & 15 & 15 \\
\hline & & $1 \%$ & 9 & 9 & 9 & 9 \\
\hline & $\mathrm{R} 2$ & $2 \%$ & 12 & 12 & 12 & 12 \\
\hline & & $4 \%$ & 14 & 14 & 14 & 14 \\
\hline
\end{tabular}

\section{PEMBAHASAN}

Sumber daya alam yang memilpah di Indonesia memicu peningktan disektor penelitan sains yang sampai saat ini masih terus berlanjut. Sejak zaman nenek moyang dulu, telah digunakan tumbuhtumbuhan sebagai ramuan obat dan sampai saat ini pula terus berkembang dengan adanya penelitian dan pengujian terhadap tumbuhan tertentu yang berkhasiat sebagai pengobatan, baik didalam maupun diluar negeri. Sampel yang digunakan pada penelitian ini yaitu daun talas ketan/taro (Colocasia esculenta). Dengan dasar pemilihan sampel yaitu pada masyarakat digunakan sebagai obat bisul dan luka bakar.
Daun talas ketan/taro (Colocasia esculenta) secara empiris digunakan oleh masyarakat sebagai obat scrofula, radang kulit bernanah, psoriasis, tumor di rongga perut, berak darah, keseleo, ketombe, bisul, dan luka bakar. Sementara tangkai dan daunnya digunakan untuk pengobatan urticaria, diare, dan pembalut luka. Hal tersebut dikarenakan tanaman talas mengandung senyawa-senyawa polifenol dan saponin. Daun talas ketan/taro (Colocasia esculenta) diteliti untuk mengetahui khasiatnya yang digunakan pada pengobatan penyakit yang disebabkan oleh bakteri tertentu, sehingga dilakukan pengujian aktivitas antibakteri dengan metode difusi agar untuk mengetahui pada kosentrasi 
Aktivitas Antibakteri Ekstrak Etanol Daun Talas Ketan (Colocasia esculenta) Terhadap Bakteri Saphylococcus aureus dan Salmonella thypi Secara Difusi Agar

berapa ekstrak memberikan aktivitas sebagai antibakteri.

Pengujian skrining aktivitas antibakteri menggunakan 2 bakteri antara lain Staphylococcus aureus dan Salmonella thypi. Pemilihan mikroba ini didasarkan pada sifat patogenik. Staphylococcus aureus merupakan bakteri kokus Gram positif yang bersifat patogenik penyebab infeksi kulit dan makanan dan Salmonella thypimerupakan bakteri anaerob fakultatif, Gram negatif yang bersifat patogenik penyebab utama tifoid. Hasil pengujian skrining antibakteri dilakukan untuk mendapatkan ekstark aktif yang dapat menghambat bakteri uji. Metode yang digunakan adalah metode dilusi padat dengan konsentrasi $1 \mathrm{mg} / \mathrm{mL}$. penggunaan konsentrasi tersebut karena ekstrak dikatakan aktif jika pada konsentrasi 1 $\mathrm{mg} / \mathrm{mL}$ menunjukan hambatan pertumbuhan bakteri dan jamur, maka ekstrak tersebut potensial untuk diteliti daya antibakterinya.

$$
\text { Hasil skrining aktivitas }
$$

antibakteri menunjukan bahwa ekstrak etanol daun talas ketan/taro (Colocasia esculenta) pada konsentrasi $1 \mathrm{mg} / \mathrm{mL}$ menghambat semua bakteri uji Staphylococcus aureus, Salmonella thypi dan hasil pengujian aktivitas antibakteri secara difusi agar menggunakan kosentrasi $1 \%, 2 \%$ dan $4 \%$ menunjukan bahwa ekstrak etanol umbi talas pada bakteri Salmonella typhi memberikan aktivitas pada kosentrasi $1 \%$ dengan diamater rata-rata zona hambatan replikasi saru (1) sebesar $8 \mathrm{~mm}$ dan replikasi dua (R2) sebesar $9 \mathrm{~mm}$, kosentrasi $2 \%$ pada replikasi satu (R1) sebesar 10 $\mathrm{mm}$ dan replikasi dua (R2) sebesar 11 $\mathrm{mm}$ dan kosentrasi 4\% pada replikasi satu (R1) sebesar $12 \mathrm{~mm}$ dan replikasi dua (R2) sebesar $13 \mathrm{~mm}$. Pada bakteri uji Staphylococcus aureus memberikan aktivitas pada kosentrasi $1 \%$ dengan diamater rata-rata zona hambatan replikasi saru (1) sebesar 9 $\mathrm{mm}$ dan replikasi dua (R2) sebesar 9 $\mathrm{mm}$, kosentrasi $2 \%$ pada replikasi satu (R1) sebesar $12 \mathrm{~mm}$ dan replikasi dua (R2) sebesar $12 \mathrm{~mm}$ dan kosentrasi 4\% pada replikasi satu (R1) sebesar $15 \mathrm{~mm}$ dan replikasi dua (R2) sebesar $14 \mathrm{~mm}$.

\section{KESIMPULAN}

1. Ekstrak etanol daun talas ketan/taro (Colocasia esculenta) memberikan aktivitas terhadap bakteri Staphylococcus aureus dan Salmonella thypi

2. Berdasarkan pengujian aktivitas antibakteri secara difusi agar menggunakan kosentrasi 1\%, 2\% dan $4 \%$ menunjukkan bahwa 
Aktivitas Antibakteri Ekstrak Etanol Daun Talas Ketan (Colocasia esculenta) Terhadap Bakteri Saphylococcus aureus dan Salmonella thypi Secara Difusi Agar

ekstrak etanol daun talas ketan/taro (Colocasia esculenta) diperoleh diameter zona hambatan terbesar terhadap bakteri Staphylococcus aureus pada kosentrasi $4 \%$ sebesar $15 \mathrm{~mm}$.

\section{DAFTAR PUSTAKA}

1. Biren NS, Nayak BS, Bhatt SP, Jalalpure SS, Seth AK. The AntiInflamatory Activity of The Leaves of Colocasia esculenta. SPJ 2007; $15: 3-4$

2. Eddy NO. Inhibitive and Adsorption Properties of Ethanol Extract of Colocasia esculenta Leaves for The Corrosion of Mild Steel in H2SO4. Int J Phys Sci 2009; 4(4):165-171.

3. Hibai ARY. Uji Aktivitas Antibakteri Ekstrak Umbi Talas Ketan (Colocasia Esculenta) Secara KLTBioautografi (Skripsi). Makassar : Farmasi Universitas Muslim Indonesia, 2013.
4. Leong AC, Yoshinori K, Masakuni T, Hironori I, Hirosuke O, Hajime T. Flavonoid glycosides in the shoot system of Okinawa Taumu (Colocasia esculenta S.). J Food Chem 2009;07:004.

5. Herwin. Standarisasi Ekstrak Dietil Eter Herba Oxalis corniculata L. Jurnal As-Syifaa 2012; 04(02) : 176-189.

6. Fitriana, Rusli. Pengaruh Variasi Konsentrasi Koimbinasi Perasan Jeruk Nipis (Citrus aurantifolia S.) Dan Getah Jarak Pagar (Jatropa curcas L.) Terhadap Aktivitas Antibakteri. Jurnal As-Syifaa 2012; 04(02):176-189.

7. Djide N, Sartini, Kadir S. Mikrobiologi Farmasi Dasar. Makassar : Universitas Hasanuddin, 2005.

8. Djide N, Kadir S. Mikrobiologi Farmasi Terapan. Laboratorium Mikrobiologi Farmasi dan Bioteknologi Farmasi, Makassar : Jurusan Farmasi Fakultas MIPA, Universitas Hasanudin, 2006. 